\title{
Drug Price Transparency for Medicare and Medicaid Programs in the United States
}

\author{
LaQuita L Johnson* \\ Department of Health Policy and Management, George Washington University, USA \\ *Corresponding Author: LaQuita L Johnson, Department of Health Policy and Management, George Washington University, USA.
}

Received: May 24, 2019; Published: June 14, 2019

DOI: $10.31080 /$ ASPS.2019.03.0313

Drug transparency and prescription drug price reduction have been two focuses of the Centers for Medicare \& Medicaid Services of the United States Health and Human Services Department (HHS). Recently, the entity has ruled for direct-to consumer (DTC) television advertisements be required to provide the Wholesale Acquisition Cost (WAC) or "list price" for prescription drugs or biological products for which payment is available, directly or indirectly, through or under Medicare or Medicaid [1].

The WAC is the best cost for price transparency and comparison shopping. In the United States, Medicare beneficiaries are currently paying the WAC of medications until their deductible is met, according to HHS.2 In addition, Medicare prescription drug plans have coinsurance payments with a variety of costs for different drugs; in which, coinsurance payments are calculated based on the "list price" of prescription drugs.2 If a prescription drug is not a part of Medicare or Medicaid formulary, the WAC is typically what a beneficiary will pay [2]. Further, the WAC is good for brand-name or single-source drugs and most television advertisements reference drugs by their brand-names. Although the WAC may be higher than what consumers will actually pay, it gives consumers a reference or an anticipated cost.

The Average Wholesale Price (AWP) should not be used because it is not an accurate representation of the actual market drug price. The AWP is defined as the average price that "retail pharmacies pay for drugs from their wholesale distributor" and is $20 \%$ higher than the actual wholesale price [3]. It is often a "soft number cost" that is a percentage of the actual wholesale price and not a whole number leading to discrepancies [4]. Additionally, the AWP has previously resulted in Medicaid paying more for certain medications because of its "benchmark" price [5]. Furthermore, the Average Acquisition Cost (AAC) and the National Average Drug Acquisition Cost (NADAC) should not be used as well. Both focus on the average price of "retail pharmacy acquisition costs for drugs through a review of actual pharmacy invoices" [3]. Although the ACC and the NADAC provide the estimated price after pharmacy discounts, it does not include the rebates from manufacturers [6].

Moreover, a 30-day supply and/or a typical course of treatment are appropriate metrics for consumers to calculate the cost of a drug. This reflects the actuality of consumers using single-source brand drugs. A 90-day supply is recommended for maintenance medications, chronic conditions, and/or medication adherence [7]. Moreover, a 30-day supply will allow consumers to access their affordability of prescription drugs. It will be easier for consumers to calculate their monthly expenses rather than their quarterly expenses. Likewise, most Medicare beneficiaries have a fixed, monthly income; in which, a 30-day will be more feasible for their budget.

More, this rule only applies to television advertisements; however, it should use other media formats such as magazines, newspapers, radio, etc. Drug manufacturers used multiple mediums to increase utilization of their products; therefore, the same mediums should be used to inform consumers about drug prices. The use of multiple channels will increase the awareness of drug prices, increase accessibility of drug prices, and increase the availability of different audiences being reached.

\section{Bibliography}

1. National Archives and Records Administration. Medicare and Medicaid Programs; Regulation to Require Drug Pricing Transparency (2019).

2. United States Department of Health and Human Services. What You Need to Know About Putting Drug Prices in TV Ads (2019).

3. US Pharmacist. Understanding Drug Pricing.

4. Berndt ER and Newhouse JP. "Pricing and Reimbursement in U.S. Pharmaceutical Markets: Faculty Research Working Paper Series". Harvard Kennedy School of Government. (2010): RWP10-039. 
5. United States Department of Health and Human Services. Replacing Average Wholesale Price: Medicaid Drug Payment Policy.

6. The University of Maryland School of Pharmacy. Transferability of Economic Evaluation Studies: Is There a Generally Accepted Alternative Price Benchmark to the WAC Price?.

7. Liberman JN and Girdish C. "Recent trends in the dispensing of 90-day-supply prescriptions at retail pharmacies: implications for improved convenience and access". American Health and Drug Benefits 4.2 (2011): 95-100.

Volume 3 Issue 7 July 2019

(C) All rights are reserved by LaQuita L Johnson. 